\title{
Evaluation of Failure Probabilities of Mechanical Systems under Seismic Action by the Monte-Carlo Simulation Method
}

\author{
M. Labou \\ Mechanical Engineering Department, University of Quebec, Montreal, Canada \\ УДК 539.4 \\ Оценка вероятности разрушения механических систем при
сейсмическом воздействии с помощью метода моделирования
Монте-Карло
}

М. Лабу

Отделение машиностроения при Квебекском университете, Монреаль, Канада

Прямой метод моделирования Монте-Карло играет важную роль в современньх расчетньдх методиках. Для больиого класса многомерньхх задач радиационной пеории переноса полько данный метод позволяет рассмотреть все геометрические и физические допущения. С помощью метода можно решить пакие актуальнье и практически важнье проблемь, как нейтронньй перенос, экранирование реактора и диффузия примесей в случайньх областях Метод позволяет оценить вероятность первого прохождения события, при котором отклик системь выходит за рамки заданной безопасной области. Оценивается вероятность разрушения пластины, подвергнутой сейсмической нагрузке. Расчет надежности системь проводится по критерию Мизеса, с полоцью которого определяется предельное состояние разруиения пластинь. Для описания сейсмической нагрузки используется предложенная Руисом и Пенцьеном статистическая модель ускорения грунта, вызванного землетрясением.

Ключевые слова: метод моделирования Монте-Карло, вероятность первого прохождения, оценка надежности, критерий Мизеса, ускорение грунта.

Introduction. The need for a stochastic analysis of engineering systems stems from the fact that an important class of structural loads, which evolves with time, exhibits a strong variability in both intensity and frequency content. This class encompasses environmental loads (e.g., wind loads on tall buildings and bridges, hydrodynamic forces on offshore and marine structures, seismic loads on buildings and dams), as well as loads caused by human activity (e.g., traffic loads on bridges, blasts and explosions, loads imposed by industrial machinery).

During the initial of the design stage, it is a common practice to perform a structural analysis by treating these loads as pseudo-static and the initial loads at a later stage. Implementation of the deterministic techniques is feasible in a routine fashion, provided that both structural properties and excitation vectors can be precisely described. There are certain cases however, for which the excitation process and/or certain structural characteristics are either unknown accurately or are random in nature [1]. Usually these are hazards due to natural phenomena 
such as earthquakes, winds, or sea-waves which result in loading processes that are not only mathematically complex, but also exhibit a strong element of randomness. Such time-dependent excitation processes are called random (or stochastic) processes. Thus, it is almost certain that any future event will result in a loading realization which will differ, to certain extinct, from all previous records that are currently available. In such cases, an effort to compute a unique deterministic solution of the dynamic problem, which will probably never be realized during the lifetime of the structure, is of little practical value.

The response of a structural system is difficult to predict when uncertainty stems from the probabilistic nature of the loading function. In other cases, uncertainty refers to the parameters of the structural system itself, (e.g., the exact nature of the constitutive law for materials used, geometric imperfections due to accidental errors in the construction process). The complexity in the analysis procedure increases, when uncertainties in both the loading process and the structural system are combined. So, the random nature of loads affecting structures as well as uncertainties associated with their resistances necessitates a probabilistic approach to the analysis of structural safety.

In the design of structural systems, safety is an important issue to be considered. Reliability, which is defined as the probability that the system meets some specified demands for a specified time period under specified environmental conditions is used as a probabilistic measure to evaluate the reliability of structural systems. The performance function of a structural system must be determined to describe the behavior of the system and to identify the relationship between the basic parameters in the system. The concept of reliability has become a power tool which enables designers to deal probabilistically with uncertainty, when sufficient knowledge of the random variables and functions is available [2-4].

The number of uncertainties involved in a joint environment system behavior is large. The seismicity is random in recurrence magnitude and location and generated by a number of independent sources. The performance of the components is random. Moreover, the system occupies such a large environment that it is never uniformly affected. However, the effects of earthquakes are transmitted indirectly, through the flow alterations in the network, to sites far beyond the felt area of an earthquake. It is readily seen, that the modeling of the stochastic process, given such a number of probabilistic degrees of freedom, constitutes a challenge to any earthquake engineering approach to the problem. Then, the modeling of the system is a separate complex task, if it is to be stochastically analyzed. Moreover, the risk analysis can not be undertaken without setting adequate performance criteria [5].

Performance criteria that are usable from the macroscale point of view have undergone research by Duke and Moran [6]. In the field of system modeling, for instance, there has been research of analytical solutions to spatially distributed networks subjected to seismic hazards [7]. However, it is felt that a more complete development in the network seismic performance field has been precluded by the limitations of purely analytic methodologies. Therefore, different approaches to the problem have to be devised, and one promising methodology is computer simulation. 
Computer simulation has been defined as an experimental arm to operations research, and as a method that abstracts the essence of problems revealing their underlying structures [8]. Analytical models convolve one fundamental relationship with the next to build up an overall final model. Simulation, on the other hand, structures the overall model chaining the elemental submodels that much resembles the actual concatenation of events in the real system. Flexibility is gained to interactively improve the model, and physical insight to the problem is retained for the iconic nature of the procedure. More important, simulation is frequently the only available solution to problems that cannot be approached analytically. Computer simulation takes samples of the probability distribution functions found along the process by means of random number generators [9]. This sampling procedure is called Monte-Carlo simulation technique.

1. General Characteristics of the Monte-Carlo Simulation Method Numerical simulation of random fields is one of the cornerstone problems of stochastic dynamics. In fact, the Monte-Carlo method and the process of stochastic field realizations are essentially two sides of the same coin; thus, the first method is used for computing statistical measures of random field from its realizations, while through the second method sample values of the field are produced from its statistical measures. We note here that the Monte-Carlo simulation method is completely general and its range of applicability is very wide. It is used for solving problems in mathematics, physics and engineering, as well as in other scientific disciplines, by conducting what are essentially sampling experiments. The method is especially valuable in cases where closed-form solutions to a problem are either impossible or extremely difficult to come by. For all practical purposes, MCS method is considered exact and is often used to gaging results produced by other methods; its basic features for stochastic dynamic problems can be most advantageously explained for the first passage problem.

The Monte-Carlo simulation method is the natural result of the interaction between the probability and computers. Several methods are currently available to solve a large number of problems in mechanics involving uncertain quantities described by stochastic processes, fields or waves. At this time, Monte-Carlo simulation appears to be the only universal method that can provide accurate solutions for certain problems in stochastic mechanics, involving nonlinearities, system stochasticity, stochastic stability, parametric excitations, large variations of uncertain parameters, and that can assess the accuracy of other approximate methods such us perturbation, statistical linearization closure techniques, stochastic averaging, etc. [10].

The combination of the finite-element and Monte-Carlo methods was facilitated by Yamazaki, Shinozuka, and Dasgupta [11]. This is one magnificent example of incorporating a powerful deterministic technique into stochastic analysis. In this regard, one should mention that presently the stochastic finiteelement method usually uses, either directly or indirectly, the perturbation method. Shinozuka and Yamazaki [12] state that Monte-Carlo simulation methods can provide useful alternative for problems to which the perturbation method does not apply when the degree of the material property variability becomes large.

The solution of problems by the MCS method consists of three stages: simulating sufficiently representative samples of stochastic values and stochastic 
processes, describing properties of a system and inputs; multiple analysis of a corresponding deterministic model aimed at obtaining samples of output parameters and processes; statistical processing of the results including the estimation of probabilistic characteristics. Since most of the methods require the use of computers, their use implies also selection of a discretization scheme to approximate the given model. In particular, discretization with respect to time is performed, and stochastic functions of continuous time are substituted by corresponding stochastic sequences [13-15].

The name 'Monte-Carlo' dates from 1944, and was introduced by von Neumann in the course of work on neutrino diffusion for the atomic bomb. Formal development of the method took place a few years later in the paper by Metropolis and Ulam [16].

2. Concept of Reliability Theory. Methods for stress analysis and for the analysis of deformations and displacements in mechanical systems are given by the theory of vibrations and by mechanics of deformable bodies. The final judgment regarding the suitability of a system under design or a system in use should be based on the theory of reliability. From the point of view of mechanics that part of reliability theory is of greatest interest in which failure is treated as the result of time changes in the system's parameters (general, physical or parametric theory of reliability). To a great extent, this theory is based on the analysis of fluctuations of random processes and fields describing the system behavior [13].

Failure is defined as complete or partial loss of the ability of the system to fulfill its functions. Failure can be caused either by the development of defects which have already been in the system by the time it came into use, or by accumulation of damages and irreversible changes occurring in the process of the system's operation. The initial distribution of defects, operating conditions, and interaction of the system with the environment are generally of random nature. Therefore, failures should be considered as random phenomena.

It is widely accepted that the mathematical probability theory is a rational and natural basis for the modeling of structural reliability problems $[17,18]$. The physical variables are taken to be random variables and the reliability with respect to a given failure mode is simply defined as the probability that the set of these random variables gets an outcome in the safe set which itself may be modeled as a random set. The complementary probability is the probability of structural failure in the considered failure mode. The performance function of a structure system must be determined to describe the behavior of the system and to identify the relationship between the basic parameters in the system. Simulation techniques are used for evaluating the degree to which a system fulfills a number of performance and design requirements during a period $\tau$, referred to as lifetime. These requirements restrain the acceptable values of the response process $X(t)$ to an open set $D_{s} \subseteq R^{n}$, referred to as the safe set. The probability

$$
P_{s}(\tau)=P\left\{X(t) \in D_{s}, 0 \leq t \leq \tau\right\}
$$

that design conditions are satisfied during projected lifetime $\tau$ provides a useful measure of system performance and is called reliability. The complement of $P_{s}(\tau)$, 


$$
P_{F}(\tau)=1-P_{s}(\tau)
$$

represents the probability of failure. Since exact values of these probabilities are difficult to obtain, approximations of and bounds on reliability and failure probability are focused on. The mean value $E\left\{N_{D}(\tau)\right\}$ of the number of excursions of $X(t)$ outside $D_{s}$, or the mean number of $D$-outcrossings of $X(t)$ in $\tau, N_{D}(\tau)$ is one of the essential parameters for approximating and bounding reliability. Reliability is equal to the probability

$$
P_{s}(\tau)=P\left\{T_{D}>\tau\right\},
$$

that the time $T_{D}$ to the first $D$-outcrossing of $X(t)$ exceeds $\tau$.

Mechanical systems may not meet performance or design specifications due to a variety of failure modes that can occur during design lifetime $\tau$. The way in which a system fails depends on material properties, system characteristics, and loading conditions. System performance relative to many failure modes can be formulated as in Eq. (1) or (2) [19].

3. First-Passage Statistics. The first-passage problem refers to the problem of determining the probability that the response of a randomly-excited dynamical system will reach the boundary of a bounded domain of state space within its projected lifetime [19]. By appropriate choice of the "safe" domain, probabilities of failure (or survival) can provide important measures of the performance and reliability of a mechanical or structural system. This approach is particularly well suited for systems, which immediately fail as soon as a response quantity overcomes a threshold.

When the random excitations can be modeled as white Gaussian noise processes, reliability analyses can be based on the strong mathematical foundation given by the theory of Markov diffusion processes. Response probability density function (p.d.f.), distribution and moments of first-passage time can then be determined as the solution of diffusion-type equations. Presently, available solutions to the first-passage probability problem are quite rare. There is a complete absence of analytical exact solution in closed form, and numerical procedures based on the Fokker-Planck-Kolmogorov equation, which are practically limited to scalar diffusion processes, are confined to problems of low dimension [20]

Due to its practical importance, the first-passage problem has attracted a great deal of attention. In a larger context, it can be considered as part of the more general question of the stability of stochastic motion. Many definitions of varying degree of importance have been given for the stability of stochastic dynamical systems [21]. The stochastic stability of parametrically excited systems in terms of first-passage times of the system response (according to Katz and Schuss, [22], and Klosek-Dygas et al., [23]) is defined as follows: if the probability of obtaining a finite first-passage time approaches zero, then the oscillator is stochastically stable, and conversely, if the first-passage time is finite with probability one then the oscillator is stochastically unstable.

Here, whether stability in a stochastic sense is guaranteed or not, a measure of reliability of a randomly excited system is defined by determining the mean 
first-passage time of the response to a closed contour specified in terms of a Lyapunov function of the system. The system will perform reliably if this time is much larger than the projected lifetime of the system (see, e.g., Roy, [24]).

4. Earthquake-Induced Ground Acceleration. The theoretical development in stochastic dynamics and reliability analysis provides the basis for establishing stochastic models for physical phenomena encountered in mechanical and structural engineering. A great number of excitations or disturbances to which mechanical and structural systems are subjected are stochastic in nature. Guided by physical insight and observations, appropriate stochastic-process models can be developed for them and used as excitations in a random vibration problem, these models can provide useful system response information.

The safety analysis of structures and other constructed facilities under earthquake loads is a typical example in random vibration since the excitation, namely ground motion induced by an earthquake, is random in general. The basic data of earthquake engineering are the recordings of ground accelerations during earthquakes. Knowledge of the ground motion is essential to an understanding of the behavior of structures under seismic action. Recorded ground motion time series contain valuable characteristics and information that are used directly, or indirectly, in seismic analysis and design. Parameters such as peak ground motion values (acceleration, velocity and displacement), measures of the frequency content of the ground motion, duration of strong shaking and various intensity measures play important roles in seismic evaluation of existing facilities and design of new systems [25].

Ground motion records can be historic or simulated; they can be created for instance from real records using an autoregressive average model. Such a simulation approach may be necessary because of the large number of iterations required to create a robust probability distribution on loss [26].

Ground motion generates inertial seismic loads, which bring into losing the load-carrying capacity of buildings. The most actual is the problem of earthquake proofing of buildings and prevention of their collapse. The solution for this problem consists in selecting a seismic load model to determine the appropriate system response. It is not possible to establish a seismic action exactly since the seismic-wave motion of the ground is a stochastic process, a concrete realization depending on many factors. Therefore, for seismic calculations, methods based on probabilistic approach are used. The white noise model is not practically used in pure form for the ground acceleration representation, since the seismic load is inherently nonstationary and has a non-uniform spectral distribution.

In this paper, a statistical model of earthquake-induced ground acceleration is used. The model was first proposed by Ruiz and Penzien [1]. According to this approach, the ground on which the structure was founded is idealized as a more or less soft soil layer resting on an underlying bedrock. The seismic waves traveling in the earth-crust hit the bedrock surface, they are filtered by the soft stratum (soil layer), and finally envelope the structure foundation.

The vibration of the bedrock is modeled by a non-stationary Gaussian process that is defined as the product of the white-noise process multiplied by a determinate function of time. Thus, a sample function of the bedrock acceleration $a_{b}(t)$ is obtained by multiplying the shape function $D_{1}(t)$ by a sample function 
$x(t)$ generated by a sequence of independent Gaussian ordinates; it is given by the following formula:

$$
a_{b}(t)=D_{1}(t) x(t)
$$

The shape function $D_{1}(t)$ for a non-stationary stochastic process is obtained by the faired curve (see Fig. 1). It depends on three parameters. When one lacks direct data, one can assume [1]: $t_{1}=1.21 \mathrm{~s}, t_{2}=11.5 \mathrm{~s}$, and $c=0.155 \mathrm{~s}^{-1}$.

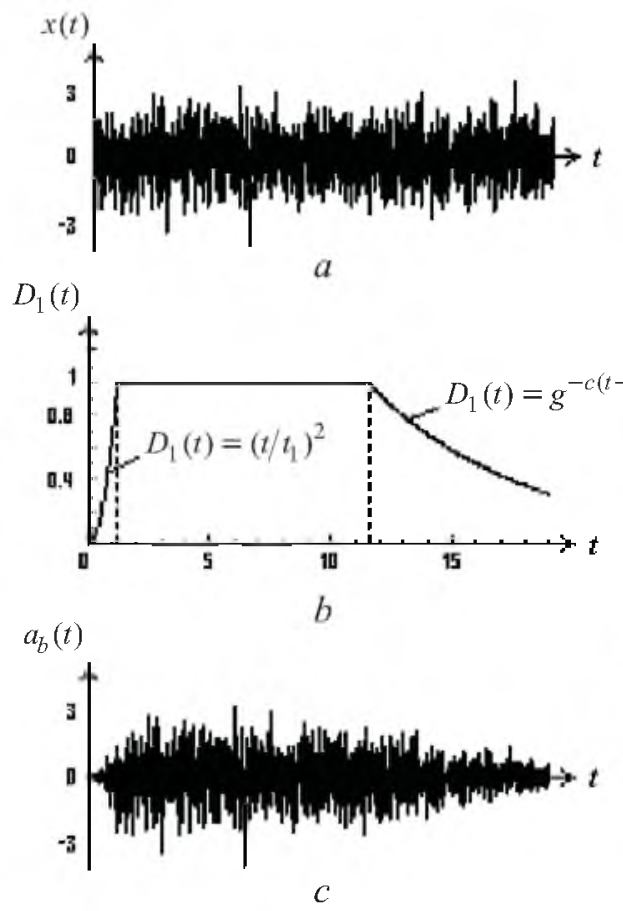

Fig. 1

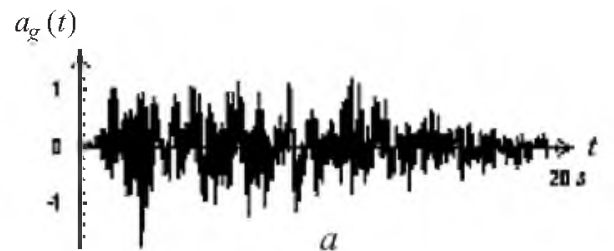

$a$

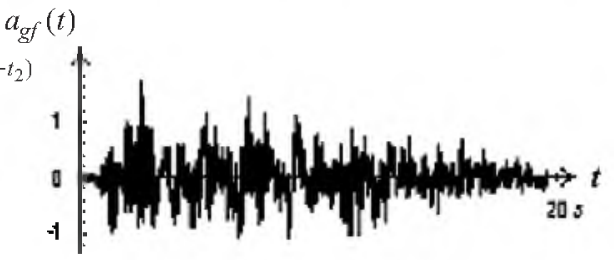

$b$

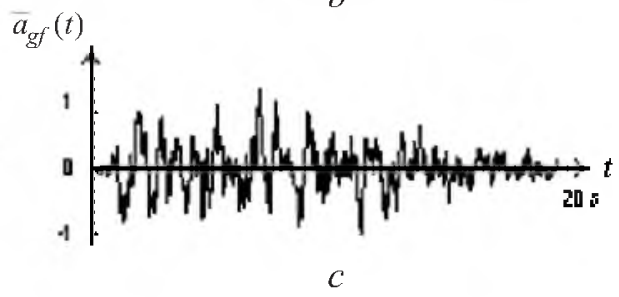

Fig. 2

Fig. 1. Simulation of the bedrock acceleration: (a) the sequence of Gaussian ordinates; (b) the shape function; (c) the bedrock acceleration.

Fig. 2. Simulation of the soil layer acceleration.

Next, filtering of the bedrock acceleration by the soil layer should be accounted for. The action of the layer is assimilated to a second-order linear filter, so that the random ground acceleration $a_{g}(t)$ at the foundation level is given by (see Fig. 2a):

$$
a_{g}(t)=-2 \xi \omega_{0} \dot{y}(t)-\omega_{0}^{2} y(t)
$$

where $y(t)$ is the solution of the differential equation

$$
\ddot{y}(t)+2 \xi \omega_{0} \dot{y}(t)+\omega_{0}^{2} y(t)=-a_{b}(t) .
$$

The parameters $\omega_{0}$ and $\xi$ may be thought of as characteristic ground frequency and characteristic damping ratio, respectively. The filter, described above, 
attenuates higher-frequency components and amplifies those in the neighborhood of $\omega=\omega_{0}$. However, it does not change the amplitude at $\omega \rightarrow 0$, and hence strong singularities are present at $\omega \rightarrow 0$. These undesirable singularities can be removed by passing $a_{g}(t)$ through a second filter (see Fig. $2 \mathrm{~b}$ ), which greatly attenuates the very-low-frequency components. Such filter is determined by

$$
\ddot{z}(t)+2 \xi_{1} \dot{z}(t)+\omega_{1}^{2} z(t)=-a_{g}(t),
$$

then it is necessary to put $a_{g f}(t)=\ddot{z}(t)$.

If $a_{p}$ is the actual peak acceleration that must be reproduced by the simulated earthquake, it is sufficient to multiply the available function $a_{g f}$ by the amplitude ratio $Y$ :

$$
\bar{a}_{g f}(t)=a_{g t}(t) Y,
$$

where $Y=a_{p} / \mu_{a_{p}}, \mu_{a_{p}}$ is the expected maximum value of the simulated sample functions $n$.

With $n$ of order 1000 , the expected peak value of the acceleration in the simulation process can be approximately set equal to three times the standard deviation $S_{a_{s}}$, i.e., $\mu_{a_{p}}=3 S_{a_{s}}$. The standard deviation $S_{a_{s}}$ of the random variable $a_{g f}(t)$ is determined by the following expression:

$$
S_{a_{s}}=S_{a_{g f}(t)}=\int_{-\infty}^{\infty} G_{a_{g f}(t)}(\omega) d \omega
$$

where $G_{a_{g f}(t)}$ is the power spectral density of the output process $a_{g f}(t)$ :

$$
G_{a_{g f}(t)}(\omega)=\left|A_{f}(\omega)\right|^{2} \cdot|A(\omega)|^{2} G_{0} \quad(-\infty<\omega<\infty) .
$$

The complex transfer function $\left|A_{f}(\omega)\right| \cdot|A(\omega)|$ of the filters in Eqs. (6) and (7) are determined, respectively, by the following formulas:

$$
\begin{aligned}
|A(\omega)|^{2} & =\frac{1+4 \xi^{2}\left(\omega / \omega_{0}\right)^{2}}{\left[1-\left(\omega / \omega_{0}\right)^{2}+4 \xi^{2}\left(\omega / \omega_{0}\right)^{2}\right.}, \\
\left|A_{f}(\omega)\right|^{2} & =\frac{\left(\omega / \omega_{1}\right)^{4}}{\left[1-\left(\omega / \omega_{1}\right)^{2}\right]^{2}+4 \xi_{1}^{2}\left(\omega / \omega_{1}\right)^{2}} .
\end{aligned}
$$

For lack of experimental data on the standard ground conditions, according to [1], the following parameters can be used: $\omega_{0}=15.6 \mathrm{rad} / \mathrm{s}, \omega_{1}=0.897 \mathrm{rad} / \mathrm{s}$, $\xi=0.6, \xi_{1}=1 / \sqrt{2}$. The spectral density $G_{0}$ takes the value $\Delta t / 2 \pi$. 
5. Numerical Example. As an application, the first passage probabilities of a plate over a limit state failure are determined. For the purpose of reliability analysis, the von Mises criterion is used. As it is well known, determination of the deflections $w(x, y)$ of the plate subjected to a transverse load $q(x, y)$, as shown in Fig. 3, leads to the integration of the equation [27]

$$
\Delta \Delta W=\frac{q(x, y)}{D} .
$$

Here $\Delta \Delta$ is the differential operator

$$
\Delta \Delta=\frac{\partial^{4}}{\partial x^{4}}+2 \frac{\partial^{4}}{\partial x^{2} \partial y^{2}}+\frac{\partial^{4}}{\partial y^{4}},
$$

and $D$ is the flexural rigidity

$$
D=\frac{E h^{3}}{12\left(1-v^{2}\right)},
$$

where $h$ is the plate thickness, $E$ is the elastic modulus, and $v$ is Poisson's ratio.

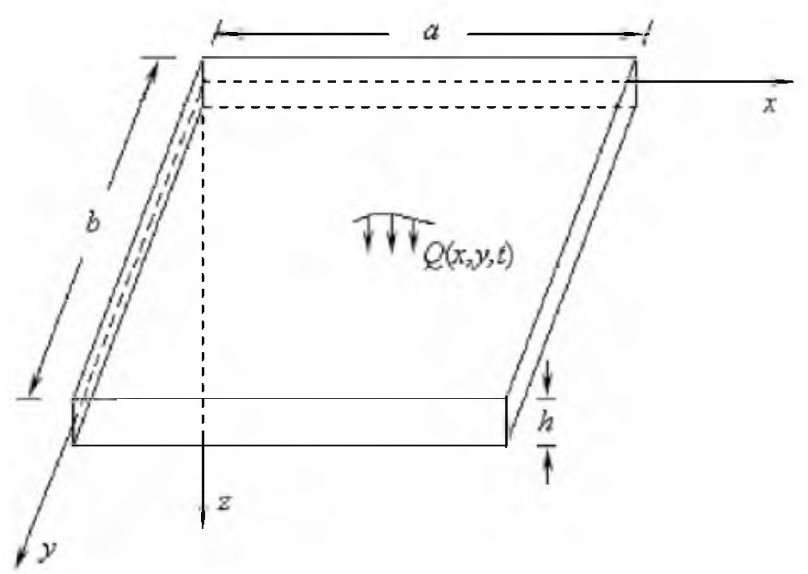

Fig. 3. Uniform plate under random dynamic load.

The plate is subjected to a parametric load with respect to deflection $W(x, y, t)$. Let this load correspond to the stresses from the plane problem of the theory of elasticity $\sigma_{x}, \sigma_{y}$, and $\tau_{x y}$. The plate is also subjected to a distributed load $Q(x, y, t)$ (considered as a seismic load), varying randomly in time and acting perpendicular to the plane of the plate. The effect of longitudinal and inertia forces can be taken into account with the help of reduced load [27],

$$
q(x, y, t)=-\left(N_{x} \frac{\partial^{2} W}{\partial x^{2}}+2 N_{x y} \frac{\partial^{2} W}{\partial x \partial y}+N_{y} \frac{\partial^{2} W}{\partial y^{2}}+\rho h \frac{\partial^{2} W}{\partial t^{2}}\right),
$$


where $N_{x}=h \sigma_{x}, N_{y}=h \sigma_{y}, N_{x y}=h \tau_{x y}$, and $\rho$ is the density of the material. The parametric forces $N_{x}, N_{y}$, and $N_{x y}$ are considered negative if they produce compression.

The differential equation for vibrations $[19,27]$ is

$$
D \Delta \Delta W(x, y, t)+c \dot{W}(x, y, t)-q(x, y, t)=Q(x, y, t) .
$$

Here $c$ is the material damping, and $\rho$ and $c$ can be functions of $(x, y)$. Let $w_{k}(x, y)$ and $\omega_{k}$ be the undamped natural modes and frequencies of free vibration of the system. They satisfy the conditions

$$
\begin{gathered}
\rho h \omega_{k}^{2} w_{k}=D \Delta \Delta w_{k}, \\
\int_{0}^{a} d x \int_{0}^{b} d y \rho h w_{k} w_{l}=m_{k} \delta_{k l},
\end{gathered}
$$

where $\delta_{k l}$ is the Kronecker delta symbol.

We seek solution in the series form

$$
W(x, y, t)=\sum_{k=1}^{\infty} X_{k}(t) w_{k}(x, y)
$$

From Eqs. (15) and (18), one can find that generalized modal coordinates $X_{k}(t)$ are the solutions of

$$
\ddot{X}_{k}(t)+2 \zeta \omega_{k} \dot{X}_{k}(t)+\left(\omega_{k}^{2}+K\right) X_{k}(t)=Q_{k}(t), \quad k=1,2, \ldots,
$$

provided that $\int_{0}^{a} d x \int_{0}^{b} d y c w_{k} w_{l}=c_{k} \delta_{k l}$. In this equation, $2 \zeta_{k} \omega_{k}=c_{k} / m_{k}$ and

$$
\left\{\begin{array}{l}
Q_{k}(t)=\frac{1}{m_{k}} \int_{0}^{a} d x \int_{0}^{b} d y Q(x, y, t) w_{l}(x, y), \\
K=\frac{1}{m_{k}} \int_{0}^{a} d x \int_{0}^{b} d y\left(N_{x} \frac{\partial^{2} w_{k}(x, y)}{\partial x^{2}}+2 N_{x y} \frac{\partial^{2} w_{k}(x, y)}{\partial x \partial y}\right. \\
\left.+N_{y} \frac{\partial^{2} w_{k}(x, y)}{\partial y^{2}}\right) w_{l}(x, y) .
\end{array}\right.
$$

We can determine probabilistic characteristic of internal forces and stresses from Eqs. (18) and (19), for example, the components of the stress tensor at a point of coordinates $(x, y, h / 2)$. At this point, $\sigma_{z}, \tau_{x z}$, and $\tau_{y z}$ are zero, so that the stress tensor represents a two dimensional stressed state, they are defined as 


$$
\left\{\begin{array}{l}
\sigma_{x}(x, y)=-\frac{E h}{1-v^{2}}\left(\frac{\partial^{2}}{\partial x^{2}}+v \frac{\partial^{2}}{\partial y^{2}}\right) W(x, y, t) \\
=-\frac{E h}{1-v^{2}} \sum_{k=1}^{\infty}\left(\frac{\partial^{2} w_{k}}{\partial x^{2}}+v \frac{\partial^{2} w_{k}}{\partial y^{2}}\right) X_{k}(t), \\
\sigma_{y}(x, y)=-\frac{E h}{1-v^{2}}\left(\frac{\partial^{2}}{\partial y^{2}}+v \frac{\partial^{2}}{\partial x^{2}}\right) W(x, y, t) \\
=-\frac{E h}{1-v^{2}} \sum_{k=1}^{\infty}\left(\frac{\partial^{2} w_{k}}{\partial y^{2}}+v \frac{\partial^{2} w_{k}}{\partial x^{2}}\right) X_{k}(t), \\
\tau_{x y}(x, y)=-\frac{E h}{1+v} \frac{\partial^{2}}{\partial x \partial y} W(x, y, t)=-\frac{E h}{1+v} \sum_{k=1}^{\infty} \frac{\partial^{2} w_{k}}{\partial x \partial y} X_{k}(t)
\end{array}\right.
$$

To determine the likelihood of failure at this point one can use the von Mises criterion. According to this criterion [19], the stressed state is acceptable if

$$
\left(\sigma_{x}+\sigma_{y}\right)^{2}+3 \tau_{x y}^{2} \leq \sigma_{c r}^{2},
$$

where $\sigma_{c r}$ denotes a limit stress. The criterion takes the form

$$
\sum_{k, l=1}^{\infty} a_{k l} X_{k}(t) X_{l}(t)<\sigma_{c r}^{2}
$$

in which

$$
a_{k l}=\left(\frac{E h}{1-v}\right)^{2}\left(\Delta w_{k} \Delta w_{l}+3\left(\frac{1-v}{1+v}\right)^{2} \frac{\partial^{2} w_{k}}{\partial x \partial y} \frac{\partial^{2} w_{l}}{\partial x \partial y}\right) .
$$
domain

Reliability $P_{s}(\tau)$ is the probability that processes $\left\{X_{k}(t)\right\}$ do not leave

$$
D=\left\{x: \sum_{k, l=1}^{\infty} a_{k l} X_{k}(t) X_{l}(t) \leq \sigma_{c r}^{2}\right\}
$$

in $(0, \tau)$. It can be calculated approximately from $D$-outcrossings of an $n$-dimensional process $X(t)=\left[X_{1}(t), \ldots, X_{n}(t)\right]$, where $n$ denotes the number of modes considered in the analysis.

Suppose that the plate is simply supported, $a<b$, and $Q(x, y, t)=Q(t)$ is a seismic load. The first four modes and frequencies of vibration of the plate are

$$
w_{k}(x, y)=\sin \frac{p \pi}{a} x \sin \frac{q \pi}{b} y,
$$


and

$$
\omega_{k}^{2}=\frac{D \pi^{4}}{\rho h}\left(\frac{p^{2}}{a^{2}}+\frac{q^{2}}{b^{2}}\right)^{2},
$$

with $((p, q)=(1,1),(1,2),(2,1)$, and $(2,2)$ for $k=1,2,3$, and 4 . Normalization constants $m_{k}$ and $c_{k}$ are equal to $\rho h a b / 4$ and $c a b / 4$, respectively, when $\rho$ and $c$ are spatially invariant.

The deflection equation of the above mentioned rectangular plate loaded with compressive edge loads $N_{x}$ and $N_{y}$ in the plane of the plate, in addition to uniformly distributed loads $P$ acting perpendicular to the plane of the plate, could be expressed in the form [28]

$$
w=\sum \sum a_{p q} \sin \frac{p \pi}{a} x \sin \frac{q \pi}{b} y,
$$

where according to [28],

$$
a_{p q}=\frac{16 P}{\pi^{6} D} \frac{1}{p q\left[\left(\frac{p^{2}}{a^{2}}+\frac{q^{2}}{b^{2}}\right)^{2}+\frac{1}{\pi^{2} D}\left(N_{x} \frac{p^{2}}{a^{2}}+N_{y} \frac{q^{2}}{b^{2}}\right)\right]} .
$$

Although both $N_{x}$ and $N_{y}$ are compressive loads, they have, a negative sign, and a value of this negative term may become high enough so that the denominator in Eq. (28) approaches zero. Under these circumstances, the deflection $w$ approaches a very large value irrespective how small the normal, $P$, may become, and the value of the edge load corresponding to this condition is known as the buckling load. For the critical values of the load parameters we obtain from Eq. (28) the relationship

$$
N_{x} \frac{p^{2}}{a^{2}}+N_{y} \frac{q^{2}}{b^{2}}=\pi^{2} D\left(\frac{p^{2}}{a^{2}}+\frac{q^{2}}{b^{2}}\right)^{2},
$$

We introduce the notations

$$
\alpha=\frac{a}{b}, \quad \varphi=\frac{N_{y}}{N_{x}},
$$

and express the buckling stresses in the following form [29]:

$$
\sigma_{x, c r}=\frac{N_{x, c r}}{h}=K_{x} \frac{\pi^{2} D}{b^{2} h}, \quad \sigma_{y c r}=\frac{N_{y, c r}}{h}=K_{y} \frac{\pi^{2} D}{b^{2} h}=\varphi \sigma_{x, c r},
$$

then from Eq. (29) we find 


$$
K_{x}=\frac{\left[(p / \alpha)^{2}+q^{2}\right]^{2}}{(p / \alpha)^{2}+\varphi q^{2}}, \quad K_{y}=\varphi K_{x}, \quad D=\frac{E h^{3}}{12\left(1-v^{2}\right)}
$$

Suppose we consider for the reliability analysis the first four modes of the plate defined in Eqs. (25) and (26). From the first equation of (20) we find that generalized forces $Q_{k}(t)$ vanish for $k=2,3$, and 4, and modal coordinates $X_{k}(t)$ are also zero for $k=2,3$, and 4 . To avoid large values of deflections due to the critical values of the load parameters, we set in Eq. (23) $\sigma_{c r}=\min \left(\sigma_{x c r}, \sigma_{y c r}\right)$, which reduces to

$$
a_{11} X_{1}^{2}(t)<\sigma_{c r}^{2}
$$

The limit state failure $x_{c}$, according to Eq. (33) is

$$
x_{c}= \pm \sigma_{c r} / \sqrt{a_{11}} \text {, }
$$

and the safe set, $D_{s}$, for $X_{1}(t)$ is

$$
\left.D_{s}=\right]-x_{c}, x_{c}[
$$

The maximum deflection is given when $x=a / 2$ and $y=b / 2$, thus from Eq. (24) we find

$$
a_{11}=\left(\frac{E h}{1-v}\right)^{2}\left[\left(\frac{\pi}{a}\right)^{2}+\left(\frac{\pi}{b}\right)^{2}\right]^{2}
$$

The parametric load acting on the plate corresponds to the stress from the plane problem of the theory of elasticity, i.e., $N_{x}=h \sigma_{x}, N_{y}=h \sigma_{y}$, and $N_{x y}=$ $h \tau_{x y}$, where $\sigma_{x}, \sigma_{y}$, and $\tau_{x y}$ are determined from Eq. (21).

For the first mode of vibration, i.e., $(p, q)=(1,1)$ the ratio $\varphi$ takes the form

$$
\varphi=\frac{N_{y}}{N_{x}}=\frac{\alpha^{2}+v}{v \alpha^{2}+1} \text {. }
$$

Thus, the expression of $K_{x}$ in Eq. (32) becomes

$$
K_{x}=\frac{\left(1 / \alpha^{2}+1\right)^{2}}{1 / \alpha^{2}+\varphi} .
$$

The case $a<b$ implies $\varphi<1$, thus $\sigma_{c r}=\min \left(\sigma_{x c r}, \sigma_{y c r}\right)=\sigma_{y c r}$, where

$$
\sigma_{y c r}=\varphi K_{x} \frac{\pi^{2}}{b^{2}} \frac{E h^{2}}{12\left(1-v^{2}\right)}
$$


The equation of motion [Eq. (19)] is reduced to the form

$$
\ddot{X}_{1}(t)+2 \zeta \omega_{1} \dot{X}_{1}(t)+\left(\omega_{1}^{2}+K_{1} X_{1}(t)\right) X_{1}(t)=Q_{1}(t),
$$

where

$$
\begin{aligned}
& Q_{1}(t)=\frac{16}{\rho h \pi^{2}} Q(t), \quad \omega_{1}^{2}=\frac{D \pi^{4}}{\rho h}\left(\frac{1}{a^{2}}+\frac{1}{b^{2}}\right)^{2}, \\
& K_{1}=-\frac{32}{9} \frac{\pi^{2}}{a^{4}} \frac{E h}{\rho\left(1-v^{2}\right)}\left[2+(1+3 v) \alpha^{2}+2 \alpha^{4}\right] .
\end{aligned}
$$

The substitution of Eqs. (36) and (39) into Eq. (34) gives the expression of the limit state failure $x_{c}$

$$
x_{c}= \pm \frac{h}{12(1+v)}\left(\frac{\varphi K_{x} \alpha^{2}}{\alpha^{2}+1}\right) \text {. }
$$

To investigate the first-passage probabilities over the limit state failure $x_{c}$, we considered a steel plate, which has the following parameters: the dimensions in plan $a=2 \mathrm{~m}, b=1.5 a$, the thickness $h=0.008 \mathrm{~m}$, the modulus of elasticity $E=210 \mathrm{GPa}$, the density of the material $\rho=7850 \mathrm{~kg} / \mathrm{m}^{3}$, Poisson's ratio $v=0.25$, the intensity of the white noise excitation $I=1 \mathrm{~m}^{2} / \mathrm{s}^{3}$, and the peak value of the ground acceleration $a_{p}=1 \mathrm{~m} / \mathrm{s}^{2}$ (Richter magnitude 7 earthquake).

Using the above data, the buckling stress from Eq. (39) takes the value $\sigma_{y c r}=3.02 \mathrm{MPa}$, which is considerably below the proportional stress limit of standard steel plate, then from Eq. (42), the limit state failure $x_{c}= \pm 3.82 \cdot 10^{-4} \mathrm{~m}$.

The differential equation Eq. (40) is integrated using the Runge-Kutta method at zero initial conditions. The first-passage probabilities of the system response $x(t)$ during time $[0, t]$ for double-sided symmetrical barriers located at $\pm x_{c}$ were determined. The response statistics with a sample size $n=300,000$ obtained by the MCS method are presented in Fig. 4.

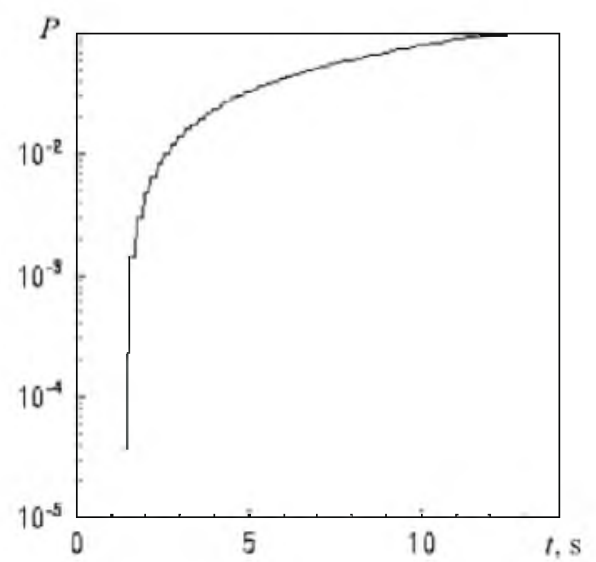

Fig. 4. Estimates for first-passage probabilities versus time for double-sided barriers located at levels $\pm x_{s}$ 
Conclusions. The research carried out shows that the Monte-Carlo simulation method allows one to assess efficiently the failure probabilities in low probability range. It has been successfully applied to a structural element, subjected to a non-stationary stochastic load action.

The fast growing computer technology made the use of the MCS method feasible; it provides a feasible solution to seismic risk analysis of spatially distributed engineering systems, and it overcomes most of the limitations of analytical approaches. A good part in its power resides in the fact that it retains a clear insight into the problem; hence, it can help to develop risk criteria.

\section{Резюме}

Прямий метод моделювання Монте-Карло відіграє важливу роль у сучасних розрахункових методиках. Для великого класу багатовимірних задач радіаційної теорії переносу тільки даний метод дозволяє розглядати всі геометричні та фізичні припущення. За допомогою методу можна розв'язати такі актуальні і практично важливі проблеми, як нейтронне перенесення, екранування реактора та дифузія домішок у випадкових областях. Метод дозволяє оцінити вірогідність першого проходження події, коли відклик системи виходить за рамки заданої безпечної області. Оцінюється вірогідність руйнування пластини при сейсмічному навантаженні. Розрахунок надійності системи проводиться по критерію Мізеса, за допомогою якого визначається граничний стан руйнування пластини. Для описання сейсмічного навантаження використовується запропонована Руісом та Пенцьєном статистична модель прискорення грунту внаслідок землетрусу.

1. G. Augusti, A. Baratta, and F. Kachiati, Probabilistic Methods in Structural Engineering, Chapman \& Hall, London-New York (1984).

2. G. D. Manolis and P. K. Koliopoulos, Stochastic Structural Dynamics in Earthquake Engineering, WIT Press, Southampton (2001).

3. M. Labou, "Solution of the first-passage problem by advanced Monte-Carlo simulation technique," Strength Mater., 35, No. 6, 588-593 (2003).

4. M. Labou, "First-passage probabilities for randomly excited mechanical systems by a selected Monte-Carlo simulation method," Ukr. Matem. J., 56, No. 7, 1196-1202 (2004).

5. H. C. Shaw and J. R. Benjamin, Lifeline Seismic Criteria and Risk: A State of the Art Report. Lifeline Earthquake Engineering: The Current State of Knowledge, ASCE, New York (1977).

6. C. M. Duke and D. F. Moran, "Guidelines for evolution of lifeline earthquake engineering," in: Proc. of the U.S. Nat. Conf. on Earthquake Engineering, Ann Arbor (1975).

7. G. Panoussis, "Seismic reliability of lifeline networks," SDDA Report No. 15, MIT Dept. of Civil Engineering, Rept. R74-57, Cambridge, MA (1974).

8. F. S. Hillier and G. J. Lieberman, Introduction to Operation Research, Holden Day, San Francisco (1974). 
9. D. E. Knuth, The Art of Computer Programming, Vol. 2, Seminumerical Algorithms, Addison Wesley Publishing Company (1969).

10. M. Shinozuka and G. Deodatis, "Simulation of multi-dimensional Gaussian fields by spectral representation," Appl. Mech. Rev., 49, No. 1, 29-53 (1996).

11. F. Yamazaki, M. Shinozuka, and G. Dasgupta, "Newmann expansion for stochastic finite element analysis," in: Stochastic Mechanics, Vol. 1, Columbia University (1986).

12. M. Shinozuka and, F. Yamazaki, "Stochastic finite element analysis: an introduction," in: S. T. Ariaratnam, G. I. Schueller, and I. Elishakoff (Eds.), Stochastic Structural Dynamics, Elsevier, London (1988), pp. 241-292.

13. V. V. Bolotin, Random Vibrations of Elastic System, Martinus Nijhoff, New York (1984).

14. V. Vikov, Digital Simulation in Statistical Radio Engineering [in Russian], Sovetskoe Radio, Moscow (1971).

15. S. Yermakov and G. Mikhailov, Course in Statistical Simulation [in Russian], Nauka, Moscow (1976).

16. N. Metropolis and S. Ulam, "The Monte-Carlo method," J. Amer. Statist. Assoc., 44, No. 247, 335-341 (1949).

17. A. M. Freudenthal, J. M. Garrelts, and M. Shinozuka, "The analysis of structural safety," J. Struct. Div. ASCE, 92, No. ST1, 267-325 (1966).

18. M. Shinozuka and H. Itagati, "On the reliability of redundant structure," in: Proc. of the Fifth Conf. on Reliability and Maintainability (New York, July 1966), Annals of Reliability and Maintainability, Vol. 5, Academic Press (1966), pp. 605-610

19. T. T. Soog and M. Grigoriu, Random Vibration of Mechanical and Structural Systems, Prentice Hall, New Jersey (1992).

20. A. A. Andronov, L. S. Pontriagin, and A. A. Vitt, On Statistical Considerations of Dynamic Systems, in: A. A. Andronov (Ed.), Collected works [in Russian], Academy of Sciences, Moscow (1956).

21. F. Kozin, "A survey of stability of stochastic systems," Automatica, 5, No. 1, 95-112 (1969).

22. A. Katz and Z. Schuss, "Reliability of elastic structures driven by random loads," SIAM J. Appl. Math., 45, No. 3, 383-402 (1985).

23. M. M. Klosek-Dygas, B. J. Matkowsky, and Z. Schuss, "Stochastic stability of nonlinear oscillators," SIAM J. Appl. Math., 48, No. 5, 1115-1127 (1988).

24. R. V. Roy, "Asymptotic analysis," Int. J. Non-Linear Mech., 32, No. 1, 173-186 (1997).

25. Y. Bozorgnia and V. V. Bertero, Earthquake Engineering, CRC Press (2004).

26. K. A. Porter, A. S. Kiremidjian, and J. S. Legrue, "Assenmbly-based vulnerability of building and its use in performance evaluation," Earthquake Spectra, 17, No. 2, 291-312 (2001). 
27. V. V. Bolotin, The Dynamic Stability of Elastic Systems, Holden-Day, San Francisco (1964).

28. E. Sechler, Elasticity in Engineering, Dover Publications, New York (1968).

29. A. Volmir, Stabiity of Elastic Systems [in Russian], Phizmatgiz, Moscow (1963).

Received 09. 10. 2007

\section{Вниманию подписчиков!}

Подписаться на журнал «Проблемы прочности» можно, как обычно, в местных отделениях связи. Журнал включен в каталоги Украины и России.

НашІ индекс - 70730.

Подписку на журнал Вы можете оформить непосредственно в редакции журнала с любого очередного номера.

Цена одного номера с учетом почтовых расходов в 2009 году составит:

в пределах Украины 30 грн. ( 6.0 USD);

за пределами Украины 300 рос. руб. ( 10.0 USD).

Почтовые переводы направлять по адресу:

01014, Киев-14, ул. Тимирязевская, 2.

Редакция журнала «Проблемь прочности»

Шинкаренко Нине Михайловне.

Справки по телефону: (044) 2865657.

Отдельным письмом необходимо сообщить в редакцию требуемое количество номеров, сумму и дату отправки перевода, указать свой почтовый адрес. Отправка журналов осуществляется после поступления денег подписчика. 